\title{
O IMPACTO SOCIAL DAS REFORMAS DA GESTÃO PÚBLICA NO NORDESTE: Notas sobre Alagoas, Pernambuco e Sergipe (2007-2013)
}

\section{THE SOCIAL IMPACT OF PUBLIC MANAGEMENT REFORMS IN THE NORTHEAST: Notes on Alagoas, Pernambuco and Sergipe (2007-2013)}

\author{
Lorena Madruga Monteiro \\ Centro Universitário Tiradentes UNIT-AL e Instituto de Tecnologia e Pesquisa ITP-SE \\ lorena.madruga@gmail.com
}

Submissão: 02/08/2016 Aprovação: 10/09/2018

\section{RESUMO}

O objetivo deste artigo foi analisar se as reformas das gestões públicas realizadas no Estado de Alagoas, Sergipe e Pernambuco impactaram os indicadores sociais destas unidades subnacionais brasileiras. Demonstra-se, através de revisão da literatura e da análise de dados secundários, que, apesar de os três Estados terem implementado reformas muito similares em suas gestões públicas, baseadas em modelos matriciais de resultados, os impactos sociais foram distintos. O Programa Alagoas tem Pressa, por exemplo, melhorou sua gestão administrativa, mas não logrou êxito em suas metas estruturantes. A gestão por Resultados implantada em Sergipe, por sua vez, permitiu um maior controle nas contas públicas e poder de investimento, que, entretanto, não se refletiu na melhora dos indicadores sociais. Na gestão por resultados implantada em Pernambuco a centralidade da atuação dos decisores, dos empreendedores de políticas públicas teve um impacto positivo no modelo. No entanto, verificou-se, nos três Estados, uma fraca associação entre a implantação das reformas baseadas em resultados na gestão pública e a melhora dos indicadores sociais. Portanto, a ideia que justifica e legitima a implantação dessas reformas da gestão pública baseadas em resultados, no caso, a questão do ajuste fiscal, não impacta positivamente os indicadores sociais, pelo contrário. Verifica-se que os Estados que não cortaram gastos substanciais na gestão pública, investiram mais, e tiveram certa melhora em seus indicadores sociais.

Palavras-chave: Reforma da gestão pública. Gestão por resultados. Indicadores sociais. Estado de Alagoas. Estado de Sergipe. Estado de Pernambuco.

\begin{abstract}
The objective of this article was to analyze if the public management reforms carried out in the State of Alagoas, Sergipe and Pernambuco impacted the social indicators of these Brazilian subnational units. It is demonstrated through literature review and secondary data analysis that, although the three states have implemented very similar reforms in their public management, based on matrix models of results, the social impacts were different. The Alagoas Program has Pressa, for example, improved its administrative management, but failed to achieve its structuring goals. The management by Results implemented in Sergipe, in turn, allowed a greater control in the public accounts and power of investment, which, however, was not
\end{abstract}


reflected in the improvement of social indicators. In the management by results implemented in Pernambuco the centrality of the action of the decision makers, of the public policy entrepreneurs had a positive impact on the model. However, there was a weak association in the three States between the implementation of results-based reforms in public management and the improvement of social indicators. Therefore, the idea that justifies and legitimizes the implementation of these results-based public management reforms, in this case, the fiscal adjustment issue, does not positively impact social indicators, on the contrary. It appears that States that have not cut substantial spending on public management have invested more and have had some improvement in their social indicators.

Keywords: Reform of Public Management. Management by results. State of Alagoas. State of Sergipe. State of Pernambuco. Social indicators.

\title{
1 INTRODUÇÃO
}

Este artigo tem por objetivo analisar os modelos de gestão por resultados implementados no Estado de Alagoas, Sergipe e Pernambuco, no mesmo período, a partir de 2007, por governos de Partidos Políticos distantes no espectro ideológico (PSDB, PT e PSB), financiados por empréstimos de organismos internacionais e impulsionados pelo Movimento Brasil Competitivo (MBC) ${ }^{1}$. Portanto, buscou-se compreender como as reformas da gestão pública foram e têm sido progressivamente impostas às administrações públicas estaduais, e os efeitos dessas mudanças em termos de gastos públicos, de indicadores sociais e políticos.

O tema da reforma da gestão pública nas unidades subnacionais ganhou corpo na primeira década dos anos 2000. Em parte, em função das denúncias de corrupção na administração pública direta durante o governo Lula, em 2005, que revelaram o patrimonialismo em vários órgãos públicos e estatais, e pela implantação, também durante o governo Lula, do Programa Nacional de Apoio à Modernização da gestão e do Planejamento dos Estados e do Distrito Federal (PNAGE), bem como do Programa de Modernização do Controle Externo dos Estados e Municípios Brasileiros (PROMEX) (ABRÚCIO, 2007). Projetos esses que retomaram algumas das diretrizes da reforma gerencial dos anos 1990, mas com nova ênfase, como discorre Abrúcio (2007, p. 78):

\begin{abstract}
O Pnage e o Promex não são os primeiros programas de modernização das instituições subnacionais comandadas pelo governo federal. No governo FHC houve avanço do Programa Nacional de Apoio à Administração Fiscal para os Estados brasileiros (Pnafe) que teve um caráter pioneiro no auxílio aos governos estaduais na área financeira. No entanto, os dois programas supracitados são diferentes, em razão de tratarem basicamente da temática da gestão pública. Depois de duas décadas de reformas nas quais a redução dos aparatos e dos gastos estatais construiu o fio condutor do processo, o Pnage e o Promoex priorizaram a reconstrução da administração pública em suas variáveis vinculadas ao planejamento, aos recursos humanos, à sua interconexão com as políticas públicas e ao atendimento dos cidadãos.
\end{abstract}

Se, por um lado, a criação e o desenvolvimento desses programas federais impulsionou as subunidades nacionais a reformarem suas administrações públicas e seus modelos de gestão, por outro lado, a ideia de reforma e o modelo a ser implantado advêm do Movimento Brasil Competitivo (MBC). Este movimento, liderado pelo empresário Jorge Gerdau, assessorado pela consultoria de Vicente Falconi, reuniu, num primeiro momento, uma serie de empresários da Natura, Petrobrás e Gerdau, por exemplo, juntamente com lideranças do executivo, para influir nas gestões públicas locais e regionais visando a melhora dos gastos públicos e, consequentemente, a redução tributária para as empresas brasileiras. Num segundo momento, em 2012, o Movimento Brasil Competitivo (MBC) reuniu o poder Executivo, o judiciário e o 
legislativo na Frente parlamentar Mista para o Fortalecimento da Gestão Pública, visando disseminar a ideia da gestão por resultados nas várias esferas da política brasileira (MONTEIRO, 2016)

Os Estados de Alagoas, Sergipe e Pernambuco optaram, em diferentes momentos, e independentemente da filiação partidária de seus governantes, pelo modelo de gestão proposto pelo MBC. Frente a estas conjunturas analisou-se, de modo preliminar, através de pesquisa com dados secundários, o impacto dessas reestruturações na administração pública nos indicadores sociais e nos gastos públicos em Alagoas, Pernambuco e Sergipe. A questão é saber se esse modelo de gestão, baseado na racionalização dos gastos públicos, e na estipulação de metas a serem cumpridas, tem o mesmo efeito nos Estados de Alagoas, Sergipe e Pernambuco, ou se outros aspectos são mais significativos na melhor promoção de serviços públicos e na melhora dos indicadores sociais.

\section{A NOVA GESTÃo PÚBLICA, A GESTÃo POR RESULTADOS E OS MODELOS MATRICIAIS}

A Nova Gestão pública (New Public Management), ou reforma gerencial, como ficou conhecida no Brasil, remete a um conjunto de ideias baseadas no racionalismo econômico que objetivaram produzir um governo que "funcionasse melhor e custasse menos" (DENHARDT, 2012, p.197). Estas ideias surgiram como resposta à crise fiscal dos anos 1970, que levou diversos países a adotarem medidas de austeridade fiscal, de contenção de gastos públicos e de incentivo a produtividade pública.

Essas novas formas de governar, que emergiram partir da década de 1970, definem-se por uma linguagem gerencialista exagerada e a introdução do racionalismo econômico no desenho organizativo dos serviços públicos (CARNEIRO; MENICUCCI, 2013). Dentre os modelos em disputa o New Public Management (NPM), destacou-se por confrontar as doutrinas básicas da administração pública substituindo a ênfase em regras gerais para a ênfase nos resultados. Associado a uma visão neoliberal em termos da condução das políticas do Estado e focado na dimensão fiscal, fundamenta-se na avaliação de que o Estado se encontra hipertrofiado, uma vez que“(...) crescimento desordenado dos gastos públicos seria um sintoma da fragilidade dos mecanismos de controle democrático em garantir a prevalência dos interesses da coletividade no processo decisório da política, erodindo as bases de legitimação do Estado" (CARNEIRO; MENICUCCI, 2013, p. 138).

Portanto, hipertrofia do Estado e déficit público incontrolável, foram algumas das questões que os governos neoliberais, a partir da década de 1980, tentaram solucionar a partir da implementação de uma agenda reformista pró-mercado, objetivando a redução do tamanho e da capacidade do Estado, de sua intervenção na economia e na reestruturação de seu aparato organizacional. Dentre os países que reformularam sua administração pública, a partir de parâmetros de eficiência, o caso mais notório foi o da Nova Zelândia. A partir dessa experiência, considerada bem-sucedida, uma série de países adotaram o modelo proposto pela Nova Gestão Pública como o Canadá, os Estados Unidos, a Grã-Bretanha, e na década de 1990, o Brasil.

As primeiras experiências de reformas gerenciais ocorreram em países membros da Organização para a Cooperação e o Desenvolvimento Econômico (OCDE). Conforme Ormond e Löffleur (1999, p. 97) as reformas ocorreram "mediante uma ampla variedade de formas e em diversos contextos envolvendo preocupações e necessidades nacionais completamente diferentes". Dada essa contestação, e ao caráter normativo dos discursos de reformas gerenciais, a nova gestão pública foi considerada "uma tela vazia", pois cada experiência teve seu padrão próprio, o que dificulta uma avaliação do modelo (FERLIE et al., 1999).

Além dos países da OCDE, algumas experiências com estes princípios gerenciais ocorreram na América Latina, entretanto, "os esforços empreendidos focaram mais na redução 
de custos que na promoção de melhoras de desempenho do setor público à medida que foram motivadas principalmente por propósitos de natureza macroeconômica, com ênfase no ajuste fiscal" (CARNEIRO; MENICUCCI, 2013, p. 154). Além disso, apesar de essas experiências terem sido desenvolvidas, principalmente, nos países anglo-saxões e nos países membros da OCDE, quando reproduzidas nos países da América Latina "passou a representar as necessidades das mais diversas empresas e governos, transcendendo, portanto, as matrizes histórico-culturais locais" (PAULA, 2005, p.38).

Entretanto, apesar de essas experiências se basearem em princípios normativos e parâmetros similares, "essas reformas administrativas consolidam novos discursos e práticas derivadas do setor privado e os usam como benchmarks para organizações públicas em todas as esferas de governo" (SECCHI, 2009, p. 348). Esses novos discursos e modelos, surgiram a partir da década de 1990, quando a New Public Management começou a ser questionada, especialmente quanto a seus resultados.

A gestão pública por ou para resultados é um dos receituários presentes nas ideias da Nova Gestão Pública. Sua primeira formulação remete à obra de Peter Drucker, publicada em 1954, na qual tal autor elaborou duas expressões: Gestão por objetivos e Gestão por Resultados. Entretanto, sua conceituação, e implementação ocorreu nas décadas posteriores, quando essa orientação foi considerada uma prática de boa governança. Conforme Silvestre (2010) a gestão por objetivos diferencia-se da gestão por resultados em termos da ênfase de ação. Enquanto "gestão por objetivos centra-se na formulação e decisão dos objetivos" (SILVESTRE, 2010, p. 174), sem dar um peso especial ao controle, monitoração e desempenho, a gestão por resultados "privilegia um feedback permanente e contínuo de todo o sistema organizacional, ao invés da formulação única dos objetivos" (SILVESTRE, 2010, p. 174). O Quadro 1 sistematiza a diferenciação estabelecida por Silvestre (2010):

\section{Quadro 1 - Gestão por objetivos x Gestão por resultados}

\begin{tabular}{|l|l|}
\hline \multicolumn{1}{|c|}{ Gestão por objetivos } & \multicolumn{1}{c|}{ Gestão por resultados } \\
\hline Abordagem top-down & Abordagem top-down \\
\hline Ênfase nos objetivos & Ênfase nos resultados \\
\hline Processo de gestão linear & Processo de gestão linear \\
\hline Não desenvolve a gestão estratégica & Desenvolve a gestão estratégica \\
\hline $\begin{array}{l}\text { Não existe ligação entre a gestão e a política de } \\
\text { trabalho }\end{array}$ & Gestão acoplada com a política de trabalho \\
\hline Organização do trabalho de tipo taylorista & Organização do trabalho de tipo pós-taylorista \\
\hline
\end{tabular}

Fonte: Elaborado pela autora a partir de Silvestre (2010).

Portanto, são modelos que dependem da burocracia decisora do topo (top-down) que se diferem no modo de gerir a organização pública e em suas ênfases. Embora o modelo orientado por objetivos tenha sido aplicado em alguns países, e tenha a mesma natureza do modelo de resultados, interessa-nos detalhar mais o modelo de resultados por ser aquele que tem sido aplicado no Brasil, recomendado pelas agências internacionais e pelos grupos empresariais.

\subsection{Os Modelos Matriciais de Gestão por Resultados}

A partir da década de 2000 uma série de consultores de organizações públicas e/ou privadas e de organizações internacionais no Brasil e no exterior vêm refletindo e defendendo o modelo de governança matricial, principalmente, a partir de 2004, nos congressos internacionais do Centro Latino-Americano para o desenvolvimento (CLAD). Conforme Souza (2008, p. 34):

Esse modelo de gestão foi apresentado pela primeira vez no IX Congresso Internacional sobre a reforma do Estado e da Administração Pública, congresso 
realizado pela Centro Latino-Americano de Administração para o DesenvolvimentoCLAD, em Madri, em 2004. Apesar de pouco tempo apresentado ao público, esta metodologia já foi utilizada como base metodológica em mais de 20 projetos em diversos órgãos públicos e entidades sem fins lucrativos.

Os modelos matriciais de governança refletem uma ideia de alinhamento interno de objetivos de dado governo. Recomendados a partir da década de 1990 pela OCDE constroemse em oposição a uma concepção de que os governos vivenciam um excesso de fragmentação que produz um aparato estatal complexo e pouco eficiente em termos de governança.

O consultor do instituto Publix, Humberto Falcão Martins, que foi gestor no Ministério do Planejamento e Gestão em 2003, da Secretaria da Reforma do Estado do Ministério da Administração Federal e Reforma do Estado (1993-1995), dentre outros cargos, confirmou os preceitos da OCDE de que a avaliação da boa governança era critério fundamental para atração de investimentos econômicos na esfera nacional, assim como nas subnacionais. (MARTINS, 2004).

$\mathrm{Na}$ avaliação de Martins (2004), em consonância com a avaliação da OCDE, a fragmentação em que os governos operam é resultado de um processo desordenado e inconsistente de formulação e implementação de políticas. A solução diante da fragmentação da gestão governamental, conforme Martins (2004), é a implementação de modelos integrativos, como o matricial. O consultor destaca, nesse sentido, o papel da liderança executiva para a integração de políticas; o plano estratégico governamental; a estrutura de governança; e a possibilidade de coordenação negociada, de conhecimento dos processos legais e administrativos (estrutura) e de uma comunidade epistêmica coerente com o projeto. Portanto, na perspectiva do consultor o modelo matricial integrado traz, supostamente, melhores resultados que o "fragmentado" para a gestão pública, uma vez que "o governo matricial está voltado à integração entre áreas de governo e outras extra-governo para alcance de resultados comuns" (MARINI; MARTINS, 2004, p. 6).

Segundo Marini e Martins (2004) para a implantação do modelo ou governança matricial é preciso repensar o processo de planejamento governamental. Ele deve ser adequado ao contexto social e organizacional que será implementado. É preciso entender a dinâmica organizacional (estrutura, gestão orçamentaria e financeira, pessoas e sistemas de informação), segundo os autores, para que as escolhas do planejamento sejam adequadas. A reinvenção do planejamento requer

[...] que este seja pensado como um processo de construção futuro que tem um lado técnico e outro político. Ainda assim, isto não implica que o lado técnico resulte em um produto tecnocrático de uma elite de técnicos ou área de governo. Mas o lado político requer que o líder político, o executivo principal na qualidade de empreendedor, seja propositor e negociador de uma visão, buscando aliados na sua direção. Nesse sentido, é fundamental que a visão exprima uma meta mobilizadora. (MARINI; MARTINS, 2004, p. 9).

Segundo os autores o primeiro passo do planejamento é a definição de alternativas estratégicas, que envolvem considerar o contexto, a análise prospectiva de cenários (potencialidades locais e regionais e percepção das vulnerabilidades) e o estabelecimento de parcerias. O segundo passo é a formulação de um plano de desenvolvimento que seja dinâmico e de possível realização diante da realidade social e governamental. Por fim, é necessário introduzir na cultura organizacional o planejamento estratégico. (MARINI; MARTINS, 2004, p. 10).

A matriz é construída levando-se em conta a relação de causalidade entre resultados (outputs e outcomes) de programas e o conjunto de metas mobilizadoras. O resultado desse esforço é a definição de uma cartilha de programas prioritários cujos resultados sejam qualificados para alcançar as metas mobilizadoras (MARINI; MARTINS, 2004, p. 15). 
As relações de coordenação, verticais ou horizontais, e os resultados dos programas são acompanhados pelo que os autores chamam de "central de resultado" ou sala de situação que "[...] é um instrumento essencial de deliberação, uma central de ação, a partir da qual decisões corretivas, punitivas e compensatórias devem emanar com ciclos de feedback curtos" (MARINI; MARTINS, 2004, p. 16). Portanto, na sala da situação o executivo e os coordenadores e gerentes de projeto têm a possibilidade, conforme os autores, de acompanhar, controlar e, se for o caso, redefinir o rumo esperado.

Portanto, o modelo de governança matricial, como as empresas de consultoria privada entendem é uma ferramenta baseada na definição e gerenciamento intensivo das redes de governança constituídos pelos nós entre os programas e as secretarias envolvidas e a arquitetura governamental.

\section{CONTEXTUALIZANDO AS EXPERIÊNCIAS}

Esta seção expõe e analisa os modelos de gestão por resultados implementados em Alagoas, Sergipe e Pernambuco. Destaca-se o contexto de implementação, o papel dos decisores, em especial do governador, a organização e as temáticas abrangidas nesses modelos.

\subsection{O Programa Alagoas tem Pressa}

A tentativa de implantar um modelo de gestão guiado pela metodologia matricial não foi inaugurada com o programa Alagoas tem pressa, efetivamente implementado em 2011. Em 2004, durante o segundo mandato do governador Ronaldo Lessa, seguindo as diretrizes do Plano Plurianual de 2004-2007, implantou-se o Projeto de Apoio ao Fortalecimento do Planejamento e da gestão de políticas públicas no Estado de Alagoas (PROGEAL), com o apoio do Banco Interamericano de Desenvolvimento (BID) (ALAGOAS, 2003). Segundo Silva (2009, p. 147-148) o objetivo "consistia em melhor capacitar e estruturar o setor público estadual, com instrumentos de planejamento e gestão para um processo crescente de melhoria no planejamento, definição, implementação e gestão de políticas públicas, dentro de uma lógica de modelo matricial."

$\mathrm{Na}$ prática uma das frentes do programa foi a implantação de uma política de modernização dos gastos. Foi instituída uma série de medidas como, gestão da telefonia, gestão de frotas, gestão de energia, gestão de viagens e estadas, gestão da informação, gestão do patrimônio imobiliário, gestão das compras governamentais, gestão de água e esgoto, gestão de vigilância e limpeza, dentre outras que, segundo Limeira (2006), geraram, no ano de 2005, economia de 1 milhão de reais por mês. (LIMEIRA, 2006).

A outra frente do PROGEAL foi de estabelecer uma série de metas para o enfrentamento da exclusão social. A macroprioridade do governo Lessa era a questão da inserção social dos alagoanos que se encontravam abaixo da linha da pobreza. Dentre as metas estipuladas pelo governo destacavam-se: estimular o desenvolvimento da economia solidária, promover o desenvolvimento econômico sustentável e a modernização da gestão pública (NASCIMENTO; NOLASCO; COIMBRA, 2006).

Após a análise dos 54 planos integrantes do PPA 2004-2007 por 84 técnicos da administração pública estadual e da consulta à sociedade civil organizada, foram estipulados 11 programas prioritários dentro do PROGEAL (ALAGOAS, 2003). A cartilha dos programas continha, desse modo, os seguintes programas: 1) incentivo ao microcrédito; 2) erradicação do analfabetismo e de democratização do acesso à educação; 3) turismo sustentável; 4) arranjos produtivos locais; 5) agricultura para todos; 6) trabalho e renda para todos; 7) água para todos; 8) redução da violência; 9) a saúde mais perto de você; 10) Estado limpo; 11) inovação e democratização da gestão; 12) transportar é desenvolver (NASCIMENTO; NOLASCO; 
COIMBRA, 2006). Conforme Silva (2009) esta tentativa de implantação de um modelo de governança matricial em Alagoas não chegou a se concretizar de modo efetivo, devido à

\begin{abstract}
Falta de compromisso de grande parte dos gestores que ocupavam cargos estratégicos no governo, o chamado primeiro escalão; o projeto não recebeu a importância devida por parte dos envolvidos, havia um sentimento de descrédito por parte de muitos servidores; sua divulgação foi muito restrita, com pouca visibilidade no Estado [...]; o momento da sua implantação/ implementação não foi o ideal (nos últimos dois anos de governo), prazo insuficiente para um projeto daquele importância e abrangência; a estrutura do governo era muito inchada para o tamanho do Estado, as secretarias se confundiam em seus papeis; do ponto de vista do resultado, foram inexpressivos, embora reconhecendo o período de apenas 2 anos; o governo que assumiu em 2007 tinha outra proposta para o Estado, que não se adequava à estrutura daquela época. (SILVA, 2009, p. 149).
\end{abstract}

Teotônio Vilela, em seu primeiro ano de mandato, em 2007, realizou reforma administrativa que reduziu o número de secretarias de 47 para 17, e implantou, em 2008, a Gestão Estratégica Orientada para Resultados (GEOR). O GEOR, construído alinhado ao Plano Plurianual de 2008-2011, tinha por objetivo melhorar a qualidade do gasto público visando a produção de melhores resultados sociais no Estado (ALAGOAS, 2007; SILVA, 2009)

A implementação do GEOR foi impulsionada pelas recomendações do Movimento Brasil Competitivo que indicou a contratação da empresa Macroplan. Entretanto, apesar de realizar "algumas das ações previstas no cronograma de execução, diante da saída do Movimento Brasil Competitivo (MBC), que deixou de ser o patrocinador, e da falta de financiamento do Estado, não foi possível dar continuidade ao projeto de estruturação" (SILVA, 2009, p. 150).

Apesar desta constatação de Silva (2009), até a implementação do programa Alagoas Tem pressa, em 2011, conforme Silva, Anjo e Guimarães (2016), a Macroplan desenvolvia um estudo das ações do governo na construção do Plano Plurianual de 2007-2011 e realizava análises com base nos dados referentes a Alagoas, coletados e divulgados pelo Pesquisa Nacional de Amostra de Domicílios do Instituto Brasileiro de Economia e Estatística (PNAD/IBGE), de 2009.

Conforme a apresentação do programa Alagoas tem pressa, no primeiro mandato foi construída a agenda estratégica, com base nos dados disponíveis, nas entrevistas com membros do governo e lideranças, e nas orientações do governador. Essa agenda estratégica foi construída, analisada, e debatida com os secretários titulares e adjuntos do governo durante a Oficina de Planejamento Estratégico realizada em julho de 2007 (ALAGOAS, 2007).

No documento do plano plurianual de 2012-2015 enviado para o aprovação legislativa consta que, no período de 2007 a 2011, foram realizadas análises para definir as áreas prioritárias em bases de dados como o IBGE, o IPEA, Ministério da Saúde e da Educação, a Secretaria de Planejamento e Orçamento, Fazenda, dentre outras, assim como foram consultados outros planos de desenvolvimento como o planejamento estratégico da prefeitura de Maceió, o Alagoas Master Plan, o Investe Alagoas, o FICO (da associação comercial de Alagoas), Programa PAPL Alagoas: Estratégias de Desenvolvimento (2004). Consta também no documento, ainda que não nomeiem, que foram realizadas pelas equipes do consórcio Macroplan-IETS 31 entrevistas individuais com a equipe do governo e representantes de segmentos da sociedade alagoana (ALAGOAS, 2011). As áreas de resultados definidas foram as ilustradas na Figura 1:

Figura 1 - Áreas de resultados do Programa Alagoas tem pressa 


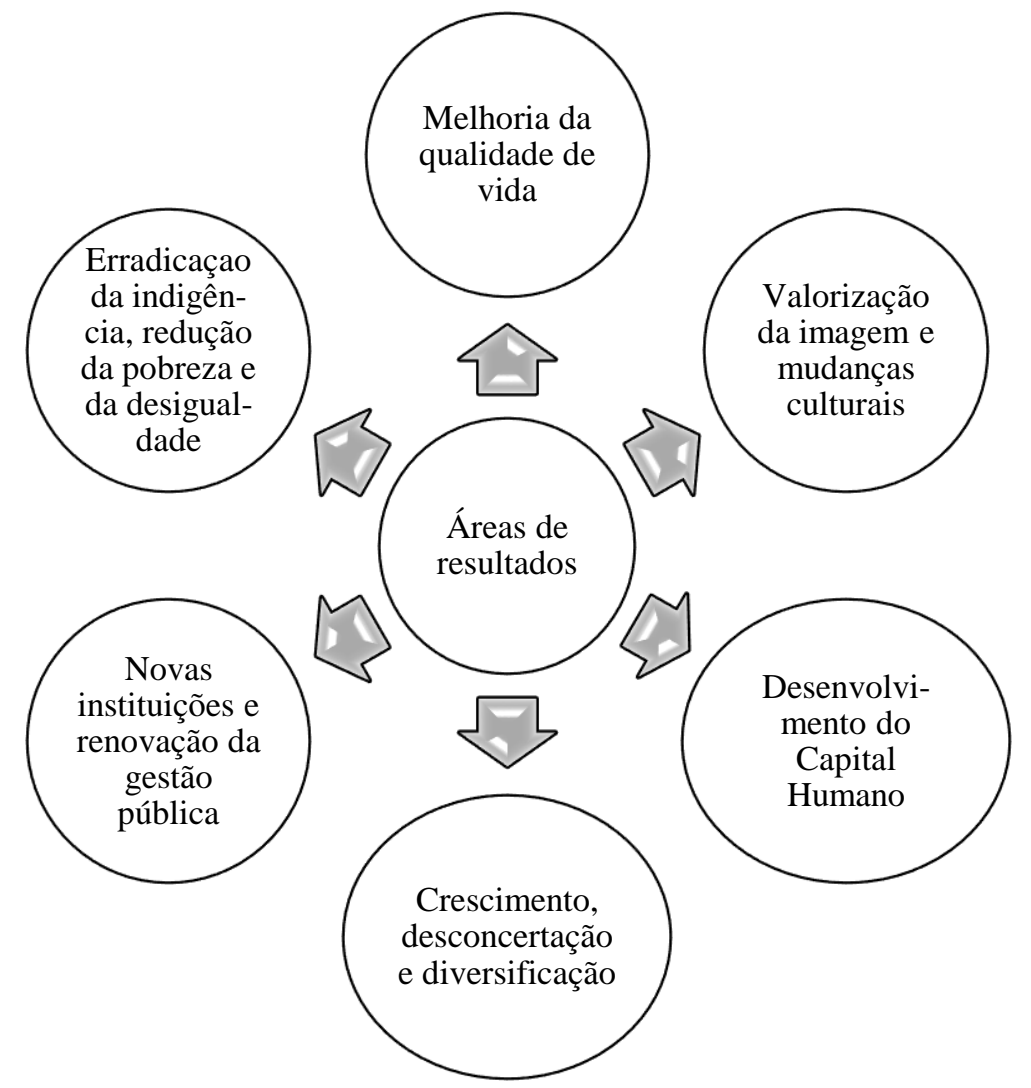

Fonte: Adaptado de Plano Plurianual 2012/2015 (ALAGOAS, 2011).

A coordenação dos 26 projetos estruturantes e dos 26 setoriais concentrou-se na Secretaria do Estado de Planejamento e do Desenvolvimento (SEPLANDE), cujo secretário administrativo, Luiz Otávio Gomes, era gestor conhecido no meio empresarial. Conforme Silva, Anjo e Guimarães (2016, p. 5) estabeleceu-se, nesta secretaria, um modelo de gestão premiado externamente, que "se tornou para o Estado o que parecia mais uma ilha de qualidade em processos gerenciais".

Segundo Silva, Anjo e Guimarães (2016) a aproximação, no Alagoas tem pressa, com a lógica do mercado privado era evidente, não apenas pela experiência do Secretário da SEPLANDE, mas, porque, dentre o quadro de gestores/e ou gerentes dos projetos quase todos eram cargos comissionados e os coordenadores das ações possuíam experiência e perfil de mercado privado. A centralidade da atuação de Luiz Otávio Gomes, que, desde 2007, no primeiro mandato de Teotônio Vilela, implementava a gestão por resultados na antiga Secretaria de Desenvolvimento Econômico, Energia e Logística (SEDEC), evidencia -se na constatação de que: "Aos 'meninos de Luiz Otavio', como ficaram conhecidos os cargos comissionados da secretaria, cabia transformar as demandas do secretário num plano de ação pelas dimensões pessoais (meritocracia), financeira, processos e liderança." (SILVA; ANJO; GUIMARÃES, 2016, p. 11).

Essa aproximação com a lógica do mercado privado, apesar de ter estabelecido um modelo de gestão premiado, gerou um ambiente conflituoso nas secretarias entre os concursados e os comissionados, assim como problemas nas rotinas administrativas. Conforme Silva, Anjo e Guimarães (2016, p. 13):

A ocorrência desses fatores de estruturação e funcionalidade inviabilizava a efetividade do Alagoas Tem Pressa. A falta de diálogo da coordenação do programa com as demais secretárias e demais poderes do governo estadual (legislativo e judiciário) implicou na falta de institucionalidade do programa e do seu relativo isolamento. Além da falta de participação da população na elaboração e 
acompanhamento do programa. O ALTP era um programa que objetivava pelo acompanhamento integrado de ações do governo transformar aspectos basilares da realidade social alagoana, no entanto sua implementação foi tecnicamente avançada, mas politicamente frágil, dado sua pouca articulação com outros poderes, bem como com a sociedade. O que nos leva a questionar sobre as reais intenções do programa e a respeito do nível de ingenuidade política dos agentes administrativos que o conceberam.

Portanto, além das questões administrativas, o programa Alagoas Tem pressa dialogou pouco para além da SEPLANDE e das demais Secretarias. Em um de seus últimos relatórios consta que, apesar de o programa visar a erradicação da pobreza, apenas 43,46\% das metas foram atingidas. Assim como na área de Melhoria da Qualidade de Vida, em que apenas 43,97\% da carteira de projetos chegou ao seu curso. Segundo a avaliação de Silva, Anjo e Guimarães (2016, p. 14) o programa teve pouco impacto social, apesar de que nas áreas "[...] mais internas a gestão (valorização da imagem e mudança cultural e Inovação na gestão pública) ou as de cunho mais econômico (crescimento, desconcentração e diversificação econômica e desenvolvimento do capital humano) faltaram em média menos de $20 \%$ para serem alcançadas".

Portanto, o programa Alagoas tem pressa, baseado na gestão por resultados, e na metodologia matricial, apesar de ter melhorado a gestão interna do Estado de Alagoas, não logrou êxito em suas metas estruturantes. Destaca-se que apesar de apresentar-se como um programa de Estado, foi um programa de governo com alta centralidade do governador e do secretário da SEPLAC na condução do programa. Nesse sentido configura-se como um programa de governo top down, no sentido atribuído por Silvestre (2010) aos programas gerencias orientados por objetivos ou resultados. O que definiu a descontinuidade do programa que, apesar de ter estabelecido metas a médio e longo prazo, foi desconfigurado na gestão posterior.

\subsection{Os Programas Modernizando a Administração Pública do Estado de Sergipe e Sergipe, Governo de Todos}

Os programas Modernizando a Administração Pública do Estado de Sergipe e Sergipe, Governo de Todos, refletem as duas gestões de Marcelo Déda, do Partido dos Trabalhadores (PT), à frente do governo do Estado. Entretanto, verifica-se, entre os dois programas, ênfases diferentes. Enquanto o Modernizando a Administração Pública concentrou-se na redução de gastos e na geração de receitas, o Sergipe, Governo de Todos, teve um caráter mais participativo.

O programa Modernizando a Administração Pública foi fruto de uma parceria entre o governo do Estado e o Movimento Brasil Competitivo, e contou com a assessoria do Instituto de Desenvolvimento Gerencial (INDG). Este programa, implementado em 2007, teve como "meta a elevação da capacidade de investimento do Estado em até R\$ 127 milhões, para os primeiros 17 meses de trabalho [...]" (TELES et al., 2009, p. 3). Conforme manifestação do governador Déda o objetivo do programa

[...] era promover avanços gerenciais sem negligenciar o cumprimento do papel essencial do Estado, que é promover o bem-estar social. Nunca quisemos cair naquilo que chamo de 'fetichismo do método', ou seja, o choque de gestão apenas movido pelo ânimo da burocracia. Fizemos do choque uma ferramenta para cumprir os compromissos assumidos com a sociedade, legitimados pelo mandato que os sergipanos me conferiram" (SECRETARIA DO ESTADO DA FAZENDA DE SERGIPE, 2009, p. 1)

Segundo Teles et al. (2009), criou-se o gerenciamento matricial de despesa, que visava a redução e o controle de despesas correntes, e o gerenciamento matricial da receita, com o 
objetivo de aumentar a arrecadação, especialmente via o ICMS e o IPVA. Conforme matéria veiculada pela Secretaria de Estado do Estado de Sergipe, no período da implantação da gestão por resultados em Sergipe, o governador Déda destacava que, até então, ocorria a inobservância da Lei de Responsabilidade Fiscal, o que dificultada o acesso pelo Estado de operações de crédito e transferências de recursos, além de pagamentos não registrados. Portanto, para o governador Déda, existia em Sergipe uma cultura gerencial anacrônica, que desperdiçava recursos públicos (SECRETARIA DO ESTADO DA FAZENDA DE SERGIPE, 2009)

A gestão por resultados foi implementada no Estado de Sergipe, inicialmente, em quatro secretarias consideradas prioritárias: Administração, Educação, Saúde e Segurança Pública. No decorrer do tempo foram incorporados os outros órgãos estaduais, totalizando, ao final, 20 secretarias e entidades estaduais comtempladas no programa. (TELES et al., 2009).

As metas estabelecidas, a partir da consultoria do INDG, foram: melhoria da qualidade do serviço; aumento da receita, sem aumento de imposto; redução das despesas, sem reduzir os serviços; valoração do servidor público. (TELES et al., 2009). A partir da identificação dos itens de maiores gastos, caracterizaram-se os pacotes de despesas que deveriam ser controlados e monitorados pelo gerenciamento matricial de despesas, como: alimentação, frota, locação de máquinas e equipamentos, imóveis, manutenção, conservação, limpeza e vigilância, materiais diversos, medicamentos e materiais de saúde, pessoal, publicidade e propaganda, serviços de terceiros, serviços médicos, tecnologia e informação (TI) e reprografia, utilidade, impostos e taxas, viagens e representações. (TELES et al., 2009).

A partir disso foram pactuadas as metas a serem seguidas e as etapas de acompanhamento mensais, através da matriz de acompanhamento de gastos mensais e acumulados de cada órgão, o relatório de três gerações, que controla o que foi realizado e prevê ações futuras para corrigir os desvios do processo. Todas essas matrizes fortaleciam, alimentavam e modificavam constantemente o plano estratégico de ação. Ao adotar essas estratégias de outubro de 2007 a setembro de 2008, o Estado de Sergipe teve um ganho real no montante de R \$ 160, 6 milhões (TELES et al., 2009). Conforme Teles et al. (2009, p. 17)

O GMD não somente alcançou seu objetivo principal de controle e redução da despesa, mas também permitiu que todos os órgãos envolvidos desenvolvessem uma prática de melhor gestão de seus gastos. A utilização da metodologia, que prevê a atualização semanal dos planos de ação e a realização de reuniões de acompanhamento com a presença das lideranças das Secretarias e do Governo, promoveu o aprendizado contínuo dos processos e a disseminação das melhores práticas.

O trabalho conjunto da consultoria do INDG com as secretarias preparou os gestores para continuarem o modelo de gestão implementado. O próprio governador Déda mostrava-se entusiasmado com o modelo de gestão, e seu prosseguimento, como ilustra sua fala: "[...]o 'livro de cabeceira' dos secretários deve ser o planejamento estratégico do Governo do Estado e que vai acompanhar, pessoalmente, os projetos de cada pasta e seus resultados." (AGÊNCIA SERGIPE DE NOTÍCIAS, 2009, p.1) Assim como sua avaliação da parceria com o MBC:

[...] O trabalho junto ao MBC superou até mesmo as previsões mais otimistas. Se no início a meta era economizar $\mathrm{R} \$ 40$ milhões e aumentar a receita em $\mathrm{R} \$ 87$ milhões, os resultados atingidos somaram uma economia de $\mathrm{R} \$ 161$ milhões e um acréscimo de receita superior a R\$ 142 milhões (SECRETARIA DO ESTADO DA FAZENDA DE SERGIPE, 2009, p.1)

O Programa modernizando a Administração Pública do Estado de Sergipe, além de controlar as contas públicas, possibilitou a atração de investimentos e empréstimos ao Estado. Essa nova configuração marcou a segunda fase da gestão por resultados nesse Estado expressa no programa Sergipe, Governo de Todos, descrito no Plano Plurianual 2008/2011 e no de 2012/ 
2015 (SERGIPE, 2007; SERGIPE, 2011). O programa Sergipe, governo de todos, teve dois objetivos centrais: Inclusão pelo Direito e inclusão pela renda.

No eixo de inclusão pelo direito na diretriz Acesso Universal à Saúde constam como metas a organização da atenção à saúde, a organização do sistema estadual de saúde, e a universalização dos serviços de saneamento básico. Em relação ao acesso universal ao serviço público de qualidade constam como objetivos: melhora na qualidade do ensino básico, educação de jovens e adultos, educação profissional e educação especial. A terceira diretriz do eixo inclusão pelo direito é dedicada à segurança dos cidadãos. Dentre suas metas consta o combate à criminalidade, descentralização do sistema estadual de segurança pública, segurança cidadão, segurança no trânsito e reestruturação do sistema penitenciário estadual. (SERGIPE, 2007)

O eixo de inclusão pela renda tem cinco diretrizes. A primeira, proteção e inclusão social, apresenta como objetivos assistência cidadã, segurança alimentar e nutricional, casa nova vida nova, inclusão produtiva de famílias e grupos em situação de risco social, sistema preventivo e protetivo, sistema socioeducativo e promoção da igualdade no ambiente de trabalho. A segunda, modernização, democratização e transparência da gestão pública, elenca como metas: a comunicação governamental, reformulação dos instrumentos de planejamento do governo estadual, modernização da gestão fiscal, valorização do servidor público e a reformulação do planejamento estratégico do Estado. A terceira, reconstrução e manutenção das rodovias estaduais, visa ampliar e melhorar a rede viária estadual. A quarta, criação de infraestrutura ambiental e de recursos hídricos, teve como metas promover a educação ambiental, instituir mecanismo de gestão e proteção ambiental dos recursos hídricos, e a construção e recuperação da infraestrutura para o saneamento ambiental. A quinta, desenvolvimento territorial participativo sustentável, objetivava desenvolver o território de maneira sustentável, promover a agricultura irrigada e familiar, e instituir o Sergipe competitivo e inovador para atrair empresas e investimentos no Estado, executar o programa luz para todos, e desenvolver uma política estadual de transportes. (SERGIPE, 2007)

Conforme o Plano Plurianual de Sergipe (2008-2011) todas essas diretrizes e metas estavam em conformidade com as metas do milênio da ONU, como a erradicação da pobreza extrema, a universalização do ensino básico, a igualdade de gênero, redução da mortalidade infantil e a promoção da sustentabilidade ambiental. Em relação ao monitoramento dos resultados, o texto do Plano Plurianual destaca o papel do líder do plano estratégico (SERGIPE, 2007).

Foram propostos 40 produtos estratégicos a serem executados em todas as secretarias do Estados. Dentre eles, conforme fala do governador, Deda, em evento nacional, uma das prioridades era o Plano prioritário de Investimentos na Segurança Pública, inclusive a implantação da gestão integrada das policias civil, militar e técnica. (SECRETARIA DO ESTADO DA FAZENDA DE SERGIPE, 2009)

O Plano Plurianual de 2012/2015 seguiu a linha do anterior, mas concentrou-se numa única meta: a erradicação da pobreza extrema no Estado de Sergipe. Essa meta desdobrou-se em quatro eixos estratégicos: desenvolvimento social e afirmação da cidadania, gestão pública de excelência, infraestrutura logística e produtiva, e desenvolvimento econômico inclusivo. No primeiro destacam-se os seguintes macrodesafios: Promoção da saúde universal, humanizada e de qualidade, ampliar e qualificar a educação e a cultura, promover a segurança pública humanizada, preventiva e com enfrentamento qualificado à violência e a criminalidade, ampliar a infraestrutura social e promover a inclusão produtiva daqueles que sem encontram abaixo da linha da pobreza. No segundo eixo colocou-se como macrodesafio implantar uma gestão pública com inovação e qualidade. No terceiro, o macrodesafio era a ampliação da integração logística e a transformação da infraestrutura urbana, e, no quarto, impulsionar a competividade 
da economia sergipana e promover o desenvolvimento com proteção aos recursos naturais. (SERGIPE, 2011)

Nesse período estava sendo implantada a sala de situação, no âmbito da Secretaria de Planejamento (SEPLAG), para o monitoramento dos projetos previstos na gestão por resultados implantada. O Plano Plurianual de 2012-2015 descreve as possibilidades de governança com a implantação da sala de situação

\footnotetext{
“por meio do Sistema de Gestão Pública Integrado (i-Gesp), será criado um módulo para acompanhamento das ações levadas a efeito no orçamento e, em fase de concepção, o módulo que permitirá, oportunamente, proceder à avaliação dos programas temáticos para aferir em que medida os resultados esperados estão sendo concretizados" (SERGIPE, 2011, p 91).
}

Também se previa no Plano Plurianual 2012/2015 que o controle dos resultados acordados pelos decisores e alto escalão do governo ocorreria no âmbito da Secretaria de Estado da Casa Civil com a implantação do Sistema online de Acompanhamento de Resultados (SOLAR) (SERGIPE, 2011).Uma distinção do modelo de gestão por resultados implementado no Estado de Sergipe, principalmente a partir deste Plano Plurianual, foi a territorialização das metas com consulta da sociedade civil. Foram definidas oito regiões Alto Sertão, Médio Sertão, Baixo São Francisco, Leste Sergipano, Grande Aracaju, Agreste, Centro-Sul, e Sul Sergipano) em que foram realizadas conferências, encontros com os gestores e sociedade civil e dentro dos marcos prioritários decidiam-se metas concretas para cada região. (SERGIPE, 2011)

Portanto, a gestão por resultados implantada em Sergipe teve dois momentos definidores. Primeiro um maior controle das contas públicas com o programa Modernizando a Administração Pública de Sergipe, que possibilitou a atração de uma série de investimentos para o Estado, e segundo, consoante as propostas do governo federal, objetivos mais amplos que levassem à erradicação da pobreza no Estado de Sergipe. O governador Marcelo Déda, embora impulsionador da ideia de gestão por restados no Estado de Sergipe, enfrentou uma grave enfermidade durante seu segundo mandato, e faleceu em 2013, o que dificultou uma análise do peso dos decisores no controle dos resultados no modelo implantado no Estado de Sergipe.

\subsection{O Programa Todos por Pernambuco}

Eduardo Campos, do Partido Socialista Brasileiro (PSB), assim que assumiu o governo de Pernambuco, em 2007, implantou, influenciado pelo Movimento Brasil Competitivo, o programa de gestão por resultados "Todos por Pernambuco". A partir de um diagnóstico dos problemas do Estado esse modelo de gestão por resultados impulsionou "a realização de uma série de mudanças na administração pública, com base em três elementos: a) construção de uma agenda estratégica; b) alinhamento da arquitetura organizacional implementadora; e, c) implantação de mecanismo de monitoramento e avaliação" (SILVA, 2016, p. 252).

Entretanto, iniciativas gerenciais não eram novidades na administração pública do Estado de Pernambuco. O governo anterior ao de Campos, de Jarbas Vasconcelos, havia implementado o Programa Pernambucano de Modernização da gestão pública (PROGESTÃO), visando controlar os gastos públicos e adequar as finanças estaduais. Conforme Silva (2016) a diferença entre os programas de Campos e Vasconcelos e os resultados alcançados explica-se pelo maior envolvimento do governador Campos do que Vasconcelos na condução do programa, e pela situação econômica do Estado, conforme Campos encontrou, em franca evolução, com a implantação do complexo logístico do Porto Suape, a fixação da refinaria Abreu Lima, da fábrica da Fiat, e do Estaleiro Atlântico Sul, assim como uma série de 
obras de infraestrutura, como a transposição do Rio São Francisco e a Ferrovia Transnordestina.

Em um relatório técnico realizado para o Banco Interamericano de Desenvolvimento (BID), Alessandro, Lafuente e Shostak (2014, p. 23) destacam algumas condições favoráveis para a implementação da gestão por resultados no Estado de Pernambuco: "1) liderança comprometida com os resultados e familiarizada com as ferramentas de gestão por resultados; 2) uma boa relação de trabalho com o governo federal; 3) uma situação fiscal saudável". Portanto, os fatores políticos, econômicos e fiscais contribuíram para a implantação desse modelo de gestão naquele período.

A partir de 2007 começou o programa de gestão por resultados Todos por Pernambuco, pautado por um diagnóstico de que a administração pública do Estado carecia de melhorar a coleta, divulgação e interpretação dos indicadores e informações estaduais, fortalecer e implantar um monitoramento efetivo, incentivar a cooperação entre instituições estaduais, etc. Segundo Alessandro, Lafuente e Shostak (2014), o modelo implantado em Pernambuco é similar aos programas de gestão orientados por dados chamados de PerformanceStat, como os implementados em Maryland e Washington.

O programa foi contratado em 2007 e sua formulação ficou a cargo de consultores de confiança do governador. Segundo Alessandro, Lafuente e Shostak (2014, p. 5)

\begin{abstract}
esses consultores, com experiência em outros órgãos do governo de Pernambuco (como a Secretaria da Fazenda e o Tribunal de Contas), empresas estatais (como a Petrobras), e consultorias privadas trabalharam durante quatro meses na criação do que viria a se tornar o Modelo Integrado de Gestão de Pernambuco.
\end{abstract}

Uma das primeiras iniciativas para implementação deste modelo integrado de gestão foi a criação de uma nova secretaria de Planejamento e Gestão (SEPLAG) em que se concentrou as atividades do Núcleo de Controle da Gestão (NCG), deixando para a Secretaria de Administração (SAD) as atividades rotineiras da administração Pública. Desse modo, todo o monitoramento estratégico ficava no âmbito da SEPLAG, como o

[...] planejamento das prioridades do governo (inclusive a participação da sociedade); alinhamento de recursos orçamentários com essas prioridades; monitoramento da execução e cumprimento das metas prioritários; e intervenção em casos de necessidade de ajustes. (ALESSANDRO; LAFUENTE; SHOSTAK, 2014, p. 5).

Alessandro, Lafuente e Shostak (2014) chamam atenção para um aspecto no programa de gestão integrada implementado em Pernambuco, tanto em sua primeira versão em 2007 quanto em sua continuidade a partir de 2011. De um lado, os autores o consideram um modelo tanto top down, pela centralidade que o governador e o alto escalão de governo tinham, e, de outro lado, bottom up, porque a sociedade participou, através de reuniões promovidas pela SEPLAG, da formulação das prioridades do governo.

Outra questão destacada pelos autores era o alinhamento das prioridades e das metas com o orçamento. O mapa da estratégia de cada objetivo tinha uma rubrica correspondente na estrutura orçamentária. Segundo Alessandro, Lafuente e Shotak (2014), isso foi facilitado, porque a SEPLAG, além de formular e monitorar as metas, era responsável pelo planejamento das dotações orçamentárias. Destaca-se também a importância da utilização, desde 2008, do sistema de gestão financeira integrado desenvolvido internamente (eFisco), espécie de aplicativo de baixo custo (Qlikview) que extrai e combina informações variadas relacionadas ao orçamento, e assim foi possível " [...] a análise de cenários fiscais alternativos para os anos seguintes, produzindo simulações e projeções que permitem aos tomadores de decisão considerar opções realistas para o financiamento das metas prioritárias (que, na maioria dos 
casos, necessitam financiamento superior a um ano) e redefinir prioridades" (ALESSANDRO; LAFUENTE; SHOSTAK, 2014, p. 12).

A centralidade dos decisores, em especial do governador Eduardo Campos, verificouse nas reuniões de monitoramento semanais, que, "segundo dados da SEPLAG, em 2013, ele ofereceu 108 horas (média de duas horas por semana) de seu tempo para presidi-las" (ALESSANDRO; LAFUENTE; SHOSTAK, 2014, p. 14). Apesar do painel de monitoramento só ter sido instalado em 2013, desde 2007, as reuniões com o governador ocorriam periodicamente. Segundo Alessandro, Lafuente e Shostak (2014, p. 13).

[...] a sistemática de monitoramento semanal pelo governador induz as secretarias e outras instituições do estado que contribuem para o cumprimento do objetivo estratégico específico a ser discutido a realizarem seu próprio acompanhamento interno para fins de preparação para as reuniões; na verdade, algumas secretarias (como a da saúde) reproduziram o modelo de acompanhamento dentro de suas próprias estruturas, com o secretario presidindo reuniões de monitoramento com os gestores das diferentes unidades que compõem a secretaria.

Os indicadores, resultados relativos às prioridades, controlados por cada secretaria distinguem-se. A SEPLAG controlava os indicadores relativos à execução física e financeira do Estado, os indicadores de processo e de produtos, e em alguns casos indicadores com impacto social também foram controlados. A secretaria de Saúde, educação e a de Segurança (Defesa Social) implementaram pactos específicos de metas, como o pacto pela saúde, pacto pela educação e o pacto pela vida. (ALESSANDRO; LAFUENTE; SHOSTAK, 2014). Em relação a este último

[...] foi instituído em 2007 (com a SEPLAG assumindo sua coordenação em 2008), ao passo que o Pacto pela educação e o Pacto pela saúde foram estabelecidos em 2011. Nessas áreas, não só os indicadores de processo e produtos são monitorados, mas também os indicadores de resultados, inclusive a evolução das taxas de homicídios e crimes violentos, rendimentos dos alunos e vários indicadores de mortalidade, respectivamente. (ALESSANDRO; LAFUENTE; SHOSTAK, 2014, p. 14).

Em relação aos mapas estratégicos, o de 2008 a 2011 contava com 10 objetivos estratégicos e 446 metas prioritárias, e o de 2012-2015 contava com 12 objetivos estratégicos e 750 metas prioritárias. Conforme o Plano Plurianual de Pernambuco de 2008-2011 essas 446 metas prioritárias estavam incluídas nos quatro eixos estruturantes de ação de governo: 1) Democratização do Estado; 2) Transposição do conhecimento; 3) Desenvolvimento econômico para todos; 4) Infraestrutura para o desenvolvimento e autosustentabilidade hídrica. (PERNAMBUCO, 2007). No Plano Plurianual de 2012/2015 as 750 metas prioritárias destinavam-se aos seguintes eixos estruturantes de ação do governo: qualidade de vida; nova economia; e, o estado do fazer. A partir de 2012 Pernambuco concentrou-se na divisão regional para implementação do seu programa de gestão verificando e monitorando as seguintes metas estratégicas em cada região: Pacto pela vida - reduzir continuamente a criminalidade no Estado; Pacto pela educação - ofertar educação de qualidade para todos; aumentar e qualificar a infraestrutura para o desenvolvimento; universalizar o acesso à agua e ao esgotamento sanitário; melhorar a habitabilidade e mobilidade; promover o desenvolvimento sustentável; alcançar uma gestão pública eficaz; valorizar o servidor e manter o equilíbrio físcal dinâmico; e, promover a sustentabilidade ambiental (PERNAMBUCO, 2011).

Portanto, a gestão por resultados em Pernambuco teve uma complexidade maior que nos outros Estados aqui analisados. As áreas essenciais de saúde, educação e segurança pública implementaram em suas secretarias programas de resultados similares ao implementado na SEPLAG, mas, com foco nos dados, nos resultados, não nos processos e produtos. Logo, descentralizou-se o modelo. Assim como houve um grande investimento em tecnologia para o 
monitoramento das metas. A centralidade na atuação dos decisores, dos empreendedores de políticas e principalmente do governador Campos teve um impacto positivo no modelo. Dinâmica essa que foi, de certo modo, interrompida pela licença tirada pelo governador Campos, para disputar as eleições presidenciais de 2014, e com a sua morte neste mesmo ano.

\section{OS RESUltados AlCANÇAdOS PELA GESTÃo POR RESUltados EM ALAGOAS, SERGIPE E PERNAMBUCO}

A melhora dos indicadores socioeconômicos era o resultado esperado dos três projetos de modernização da gestão pública implantados nestes Estados. Entretanto, embora os três Estados tenham elevado minimamente seu indice de desenvolvimento humano, continuaram, entre todos os Estados da federação brasileira, ocupando as piores posições, conforme o ranking da Organização das Nações Unidas (ONU), conforme Gráfico 1:

\section{GRÁFICO 1 - Índice de Desenvolvimento Humano estadual 2000-2010 (AL, SE, PE)}

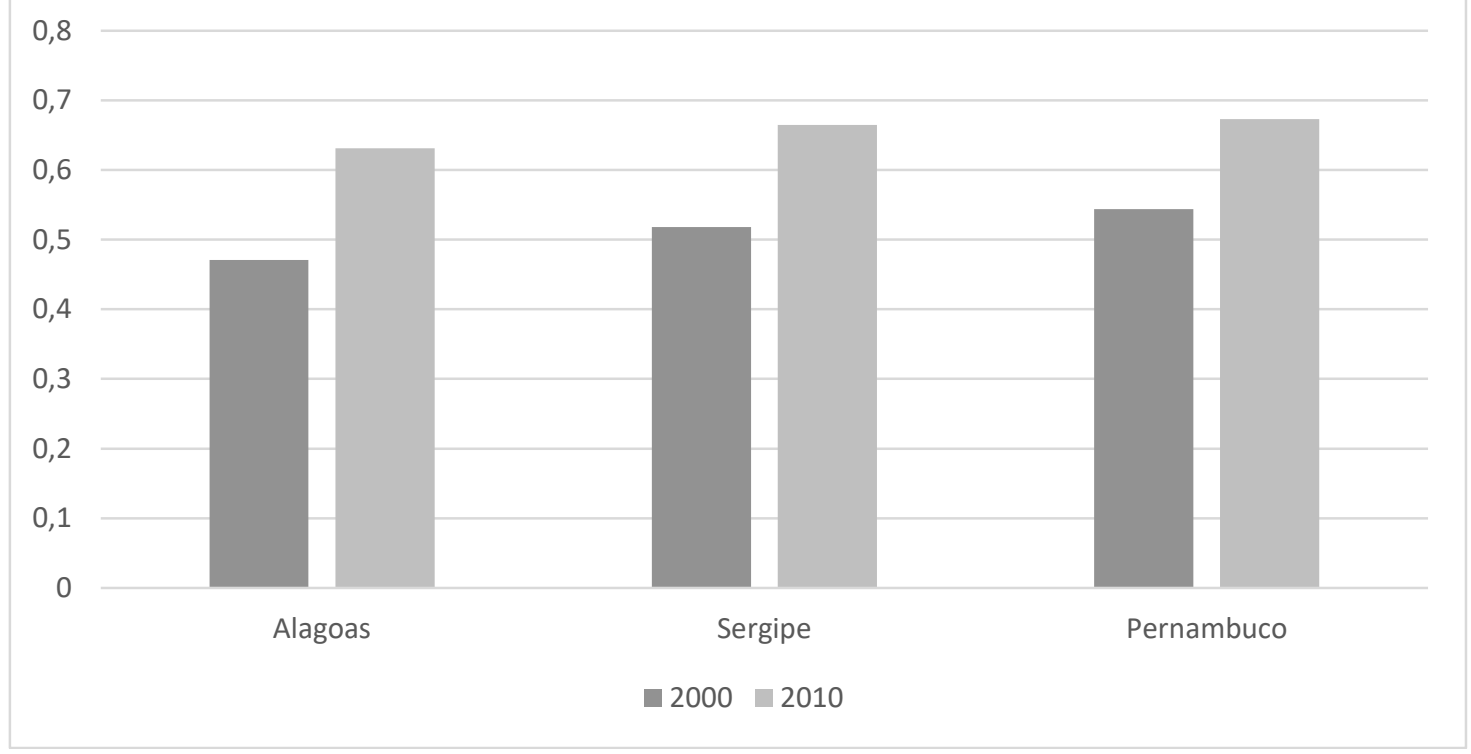

Fonte: Elaborado pela autora com dados extraídos de IPEA/DATA.

Sergipe, embora tenha aumentado seu índice, permaneceu na vigésima posição entre os Estados Brasileiros. Pernambuco que ocupava a décima-quinta posição passou para a décimanona, caindo quatro posições. Alagoas, mesmo com certo aumento no índice, permaneceu na última posição dentre os Estados Brasileiros, em vigésimo-sétimo. Portanto, em relação ao índice de desenvolvimento humano, realizado pela Organização das Nações Unidas (ONU) e composto por três indicadores - educação, longevidade e renda - Alagoas, Sergipe e Pernambuco não avançaram, ou se mantiveram na mesma posição que se encontravam em 2000, ou caíram algumas posições em comparação com os outros Estados federativos brasileiros.

A educação é uma das áreas prioritárias nos projetos de reforma da gestão pública implementados em Alagoas, Pernambuco e Sergipe. É um dos indicadores determinantes da posição que estes Estados ocupam no ranking brasileiro medido pelo índice de desenvolvimento humano estadual (IDH), como analisado. Um dos indicadores que sugerem alguma mudança nessa área é o percentual de analfabetismo, em especial na faixa etária de 10 
a 14 anos. Durante o período das reformas de gestão empreendidas por estes Estados federativos os resultados foram estes, conforme Tabela 1:

Tabela 1 - Percentual de analfabetismo em indivíduos de 10 a 14 anos

\begin{tabular}{l|c|c|c|c|c|c}
\hline $\begin{array}{c}\text { Ano / } \\
\text { Estado }\end{array}$ & $\mathbf{2 0 0 6}$ & $\mathbf{2 0 0 7}$ & $\mathbf{2 0 0 8}$ & $\mathbf{2 0 0 9}$ & $\mathbf{2 0 1 1}$ & $\mathbf{2 0 1 2}$ \\
\hline Alagoas & 7,98 & 8,86 & 7,89 & 5,27 & 5,0 & 4,59 \\
Pernambuco & 6,10 & 5,92 & 5,78 & 5,71 & 3,61 & 3,27 \\
Sergipe & 5,54 & 2,54 & 4,62 & 4,14 & 5,44 & 3,23 \\
\hline
\end{tabular}

Fonte: Elaborado pela autora com dados extraídos de IPEA/DATA.

Conforme dados da Tabela 1, em relação a Alagoas e Sergipe, Pernambuco, desde a implementação da reforma de sua gestão pública, vem reduzindo progressivamente o percentual de analfabetismo entre a população de 10 a 14 anos de idade. Alagoas e Sergipe também apresentam certa redução, em relação ao intervalo de seis anos, mas, esta redução apresentou oscilações anualmente.

Os três programas de reforma da gestão pública visavam a erradicação da pobreza. Conforme dados do IPEA de 2000 a 2010 o Estado de Alagoas, em 2010, reduziu aproximadamente $22,5 \%$ daqueles considerados pobres, $16,48 \%$ daqueles em situação de vulnerabilidade e reduziu em 15,29\% a extrema pobreza. No Estado de Pernambuco, de 2000 a 2010, reduziu-se aproximadamente $19 \%$ daqueles considerados pobres, $17 \%$ daqueles em situação de vulnerabilidade e $10 \%$ dos extremamente pobres. O Estado de Sergipe diminuiu, em 2010 , em torno de $21 \%$ do número de pessoas pobres, $18,64 \%$ do número de pessoas vulneráveis à pobreza e $12,82 \%$ daquelas que estavam em situação de extrema pobreza em 2000, conforme Tabelas 2 e 3:

Tabela 2 - Percentual de pobreza em 2000

\begin{tabular}{l|c|c|c}
\hline \multicolumn{1}{c|}{ Estado } & \% de pobres & \% de vulneráveis à pobreza & \% de extremamente pobres \\
\hline Alagoas & 56,80 & 76,24 & 31,95 \\
Pernambuco & 45,27 & 67,83 & 22,30 \\
Sergipe & 48,84 & 70,77 & 24,52 \\
\hline
\end{tabular}

Fonte: Elaborado pela autora com dados extraídos de IPEA/DATA.

Tabela 3 - Percentual da pobreza em 2010

\begin{tabular}{l|c|c|c}
\hline \multicolumn{1}{c|}{ Estado } & \% de pobres & \% de vulneráveis à pobreza & \% de extremamente pobres \\
\hline Alagoas & 34,29 & 59,76 & 16,66 \\
Pernambuco & 27,17 & 51,86 & 12,32 \\
Sergipe & 27,89 & 52,13 & 11,70 \\
\hline
\end{tabular}

Fonte: Elaborado pela autora com dados extraídos de IPEA/DATA.

Possivelmente, essa sensível melhora nos indicadores que medem a pobreza tenha tido relação com os projetos e sistemas integrativos do executivo federal, como o Programa Bolsa Família. Claro que uma gestão apta a implementar programas sociais, sejam com repasses do executivo federal, ou de caráter estadual, facilita o monitoramento e a eficiência da aplicação dos recursos e na melhora nos indicadores sociais.

Outra área considerada importante nestes programas de reforma da gestão pública é a da segurança pública. Consta, tanto no programa de Pernambuco, quanto no de Alagoas e no de Sergipe, a área de segurança pública como primordial para o êxito das reformas de gestão implantadas. Esses programas buscaram, através do monitoramento, do estabelecimento de metas, reduzir os índices de criminalidade e homicídios, por exemplo. Entretanto, desde a implantação desses Programas, em meados de 2006, os resultados obtidos nem sempre corresponderam ao esperado, como mostra a Tabela 4, em relação à evolução das taxas de homicídios. 
Tabela 4 - Taxa de homicídios na população total (por 100 mil) por UF (2005-2011)

\begin{tabular}{|c|c|c|c|c|c|c|c|}
\hline Estado & 2005 & 2006 & 2007 & 2008 & 2009 & 2010 & 2011 \\
\hline Alagoas & 40,2 & 53,0 & 59,6 & 60,3 & 59,3 & 66,8 & 72,2 \\
\hline Pernambuco & 51,2 & 52,7 & 53,1 & 50,7 & 44,9 & 39,3 & 39,1 \\
\hline Sergipe & 25,0 & 29,8 & 25,9 & 28,7 & 32,8 & 33,9 & 35,4 \\
\hline
\end{tabular}

Fonte: Elaborado pela autora com dados extraídos do Sistema de informação sobre mortalidade (SIM).

Conforme a Mapa da Violência no Brasil, publicado em 2013, as taxas de homicídios, entre todos os Estados federativos brasileiros, subiram de modo acentuado e desordenado no Estado de Alagoas. Este Estado passou, em relação ao ranking de homicídios no Brasil, da $12^{\circ}$ posição em 2001, para a $1^{\circ}$ em 2011. Inclusive, conforme Tabela 4, após a implementação do programa de reforma da gestão pública em Alagoas não se verificou nenhum recuo substantivo no percentual de homicídios; pelo contrário, ano a ano vem aumentando o número de homicídios neste Estado federativo.

O Estado de Pernambuco, ao contrário da situação do Estado de Alagoas, apresenta um panorama um pouco distinto em relação às taxas de homicídios após a implementação da reforma de sua gestão pública. Embora não possa ser considerado um avanço substancial, porque ainda é considerado um Estado com taxas altas de mortalidade, passou da $1^{\circ}$ posição no ranking de homicídios no Brasil mensurado em 2001 para a $5^{\circ}$ posição em 2011. Desde 2007, ano de estruturação e implementação da reforma de sua gestão, conforme dados do sistema de informação sobre mortalidade agregados na Tabela 4, o Estado reduziu progressivamente suas taxas de homicídios até 2011.

O Estado de Sergipe apresenta um quadro um pouco diferente de Pernambuco, mas com certa similaridade com Alagoas em relação à evolução das taxas de homicídios. Apesar de certa oscilação nas taxas entre 2005 a 2007, a partir de 2008, ano de implementação da reforma de sua gestão, verificou-se crescente elevação nas taxas de homicídios. Entretanto, conforme o mapa da violência no Brasil, de 2001 a 2011, subiu apenas uma posição, sendo considerado, em 2011, com base nas taxas de homicídios, o décimo Estado mais violento do Brasil.

Outra área importante nos programas de reforma da gestão pública implantados nestes Estados federativos, além da área de segurança pública, é a área da saúde. A ideia básica é que o ajustamento das contas estaduais, entre os gastos e a arrecadação, permitirá um maior investimento em áreas consideradas primordiais, como a saúde e a segurança pública, melhorando, assim, os indicadores sociais dos Estados. Portanto, a opção destes Estados em reformarem sua gestão pública, através de consultoria privada, objetivou, num primeiro momento, a questão da contenção dos gastos, para poderem investir em áreas como a saúde. Normalmente uma das primeiras ações governamentais nesse sentido é a contenção dos gastos de custeio da gestão púbica. Em relação aos gastos de custeio no Estado de Alagoas, Sergipe e Pernambuco o Gráfico 2 ilustra o gasto anual, de 2006 a 2010:

\section{GRÁFICO 2 - Gastos de custeio (AL, SE, PE)}




\subsection{0 .000 .000}

10.000 .000 .000

8.000 .000 .000

6.000 .000 .000

4.000 .000 .000

2.000 .000 .000

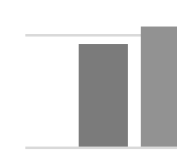
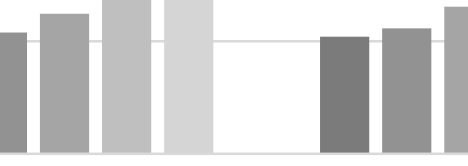

Alagoas

Sergipe

— $2006 \square 2007 \quad \square 2008 \square 2009 \square 2010$

Fonte: Elaborado pela autora com dados extraídos de IPEA/DATA.

Conforme o Gráfico 2, o Estado de Pernambuco incrementou ano a ano seu gasto com custeio na gestão pública, Sergipe manteve certa retração nos gastos, tendo leve aumento no ano de 2010, e Alagoas manteve os gastos num certo patamar, sem grandes picos de gastos de custeio. A questão é saber qual é a relação dos gastos de custeio com o gasto de áreas consideradas primordiais pelos programas de reforma da gestão pública, como a saúde, por exemplo.

A Tabela 5 mostra a proporção em relação ao PIB do gasto estadual com ações e serviços de saúde por ano.

Tabela 5 - Proporção do gasto estadual/ PIB (\%) com ações e serviços públicos de saúde,

\begin{tabular}{l|c|c|c|c}
\multicolumn{5}{c}{ por ano } \\
\hline \multicolumn{1}{c|}{ Estado } & $\mathbf{2 0 0 7}$ & $\mathbf{2 0 0 8}$ & $\mathbf{2 0 0 9}$ & $\mathbf{2 0 1 0}$ \\
\hline Alagoas & 1,90 & 2,11 & 1,92 & 1,91 \\
Pernambuco & 1,64 & 1,80 & 1,80 & 1,94 \\
Sergipe & 1,96 & 2,06 & 2,06 & 1,92 \\
\hline
\end{tabular}

Fonte: Elaborado pela autora com dados extraídos de Indicadores e dados básicos (IDB-2012).

O Estado de Pernambuco, que não reduziu os gastos com custeio, pelo contrário, aumentou anualmente, apresenta um crescente gasto em saúde, ainda que insuficiente quando comparado a outros Estados da Federação brasileira. Alagoas, por sua vez, que conteve seus gastos de custeio na gestão pública, não apresenta avanços significativos em relação aos gastos com a saúde pública. Essa relação entre gastos de custeio e investimentos na saúde pública só apresenta alguma correlação, ainda que mínima, quando comparamos os dados do Estado de Sergipe. O ano em que Sergipe eleva seus gastos de custeio é o mesmo em que reduz um pouco a proporção do gasto estadual com ações e serviços de saúde.

Entretanto, tal relação não se confirma quando se analisa o gasto estadual per capita com ações e serviços públicos de saúde, por ano. Tanto Pernambuco, que elevou seus gastos com custeio, quanto Sergipe, que apresentou um gasto moderado de custeio, aumentaram o valor per capita investido por ano na saúde, conforme Tabela 6: 
Tabela 6 - Gasto estadual per capita com ações e serviços públicos de saúde por ano

\begin{tabular}{l|c|c|c|c|c|c}
\hline \multicolumn{1}{c|}{ Estado } & $\mathbf{2 0 0 7}$ & $\mathbf{2 0 0 8}$ & $\mathbf{2 0 0 9}$ & $\mathbf{2 0 1 0}$ & $\mathbf{2 0 1 1}$ & $\mathbf{2 0 1 2}$ \\
\hline Alagoas & 109,76 & 131,43 & 129,39 & 150,57 & 149,48 & 148,43 \\
Pernambuco & 118,66 & 145,03 & 160,29 & 209,83 & 221,96 & 233,70 \\
Sergipe & 169,19 & 201,60 & 201,32 & 222,20 & 264,81 & 279,20 \\
\hline
\end{tabular}

Fonte: Elaborado pela autora com dados extraídos de Indicadores e dados básicos (IDB-2012).

Todos esses dados, referentes à educação, saúde e segurança pública, demonstram uma fraca associação entre a implantação das reformas baseadas em resultados na gestão pública e a melhora dos indicadores sociais nestes Estados.

\section{CONSIDERAÇÕES FINAIS}

Esta breve análise das experiências de gestão por resultados nos Estados de Alagoas, Sergipe e Pernambuco revelam, em sintonia com a literatura especializada, que não há um receituário pronto que leve aos mesmos resultados, pelo contrário, uma série de variáveis influenciam no processo, como a centralidade dos decisores, o relacionamento com o governo federal, uma situação fiscal confortável, o planejamento e acompanhamento dos processos, não só dos resultados, dentre outros. Essas questões ficam evidenciadas na análise dos três programas de gestão por resultados.

Destaca-se, ainda, que ao contrário do que legitima e justifica a implantação dessas reformas da gestão pública baseadas em resultados, no caso, a questão do ajuste fiscal, não impacta positivamente os indicadores sociais, pelo contrário. Verifica-se que os Estados que não cortaram gastos substanciais na gestão pública investiram mais em serviços de saúde, por exemplo, e tiveram certa melhora em seus indicadores sociais. Aliás, percebe-se que se o Estado está estável nas suas contas públicas, o receituário da gestão por resultados apresenta algum impacto.

Outra questão importante, embora não tenha sido explorada nesta pesquisa, é o impacto da captação, alocação e execução dos programas sociais federais, a exemplo do programa Bolsa Família, nos indicadores sociais destes Estados federativos. Percebe-se, mesmo sem realizar um teste específico, nos dados apresentados, uma correlação entre a implantação dos recursos federais e sensível melhora nos indicadores sociais nestes Estados. Portanto, nesse sentido, a reforma nas gestões públicas não impacta significativamente o desempenho dos indicadores sociais nestes Estados federativos, mas a implantação dos programas sociais do executivo federal.

O estudo, ora apresentado, analisou três Estados que implementaram modelos de gestão por resultados similares, o que, de certo modo, limitou a perspectiva adotada. Considera-se que, apesar das contribuições desta pesquisa, deve-se cotejar outros Estados que não implementaram esse modelo de gestão para comparar os resultados alcançados e encontrar outras variáveis que possam explicar a dinâmica da gestão pública no Brasil. Acredita-se que esse esforço analítico esclarecerá melhor o alcance desses programas. 


\section{REFERÊNCIAS}

ABRÚCIO, F. Trajetória recente da gestão pública brasileira: um balanço crítico e a renovação da agenda de reformas. Rev. Adm. Pública, Rio de Janeiro, v.41, n. spe, p. 67-86, 2007.

AGÊNCIA SERGIPE DE NOTÍCIAS. Marcelo Deda faz reunião com o secretariado. 2009. Disponível em: http://www.agencia.se.gov.br/noticias/governo/marcelo-deda-faz-reuniaocom-o-secretariado Acesso em 03 de março de 2013.

ALAGOAS. Secretaria de Estado do Planejamento e do orçamento. Plano Plurianual PPA 2004-2007, Maceió, 2003. Disponível em http://dados.al.gov.br/dataset/plano-plurianualppa/resource/077930d6-8e0c-419c-a793-b2463da81ff4 Acesso em 10 de Abril de 2014.

ALAGOAS. Secretaria de Estado do Planejamento e do orçamento. Plano Plurianual PPA 2008-2011, Maceió, 2007. Disponível em http://dados.al.gov.br/dataset/plano-plurianualppa/resource/4f429760-7864-4c57-9e98-fc4fdda61327 Acesso em 10 de Abril de 2014.

ALAGOAS. Secretaria de Estado do Planejamento e do orçamento. Plano Plurianual PPA 2012-2015, Maceió, 2011. Disponível em http://dados.al.gov.br/dataset/plano-plurianualppa/resource/560eb437-eced-42f8-89aa-d16e05b80e6 Acesso em 10 de Abril de 2014.

ALESSANDRO, M. LAFUENTE, M. SHOSTAK, R. Liderando a partir do centro: o modelo de gestão de Pernambuco. Banco Interamericano de Desenvolvimento (BID). Relatório técnico, 2014.

CARNEIRO, R.; MENICUCCI, T.M.G. Gestão pública no século XXI: as reformas pendentes. In: NORONHA, J.C; PEREIRA. T. R. (Orgs). A saúde no Brasil em 2030: prospecção estratégica do sistema de saúde brasileiro: desenvolvimento, Estado e políticas de saúde. Volume 1. Rio de Janeiro: Fiocruz/Ipea/Ministério da Saúde /Secretaria de Assuntos Estratégicos da Presidência da República, 2013.

DENHARDT, R. B. Teorias da administração pública. São Paulo: Cengage Learning, 2012.

FERLIE, E et al. The new public management in action. Oxford, Oxford University Press, 1999.

LIMEIRA, C. Finanças. In: CAVALCANTE, A. Superando a estagnação. Como Alagoas conseguiu vencer a falência da estrutura pública, avançar em questões sociais e o focar o desenvolvimento. EDUFAL, Maceio, 2006

MARINI, C. MARTINS, H. Um governo matricial: estruturas em rede para a geração de resultados em desenvolvimento. IX Congreso Internacional del CLAD sobre la Reforma del Estado y de la Administración Pública, Madrid, España, 2 - 5 Nov. 2004.

MARTINS, H. Introdução ao governo Matricial- O problema da fragmentação. In: IX Congresso Internacional del CLAD sobre la reforma del Estado y de la administración Pública. Madrid, Espanha, 2-5 Nov, 2004. 
MONTEIRO, L.M. Discurso gerencial normativo e a gestão por resultados: Notas sobre os modelos organizacionais implementados nas unidades subnacionais brasileiras. Anais do IV

Congresso Brasileiro de Estudos Organizacionais -Porto Alegre, 2016.

NASCIMENTO, C. NOLASCO, C. COIMBRA, C. Planejamento. In: CAVALCANTE, A. Superando a estagnação. Como Alagoas conseguiu vencer a falência da estrutura pública, avançar em questões sociais e o focar o desenvolvimento. EDUFAL, Maceió, 2006.

ORMOND, D. LÖFFLER, E. A nova gerência pública: o que aproveitar e o que rejeitar? In: Revista do Setor Público. Ano 50, Número 02, Abr - Jun, 1999.

PAUlA, A. P. P. de. Administração Pública Brasileira: Entre o Gerencialismo e a Gestão Social. RAE-Revista de Administração de Empresas, 45(1), 36-49, 2005.

PERNAMBUCO. Secretaria de Planejamento e Gestão. Plano Plurianual 2008/2011. Todos por Pernambuco, $\quad 2007 . \quad$ Recife, Disponível em http://www2.seplag.pe.gov.br/c/document_library/get_file?p_1_id=18613\&folderId=51243\&n ame=DLFE-3715.pdf Acesso em 10 de Abril de 2014.

PERNAMBUCO. Secretaria de Planejamento e Gestão. Plano Plurianual 2012/2015. Recife, 2011. Disponível em

http://www2.seplag.pe.gov.br/c/document_library/get_file?p_1 id=18613\&folderId=51243\&n ame=DLFE-21762.pdf Acesso em 10 de Abril de 2014.

SECCHI, L. Modelos organizacionais e reformas da administração pública. Revista Administração Pública, Rap — Rio de Janeiro 43(2):347-69,MAR./ABR. 2009.

SECRETARIA DO ESTADO DA FAZENDA DE SERGIPE. Governador expõe avanços da gestão em Sergipe durante evento nacional. 29 de julho de 2009, 2009. Disponível em http://www.sefaz.se.gov.br/noticias/governador-expoe-avancos-da-gestao-em-sergipe-

durante-evento-nacional

Acesso em: 03 de março de 2013

SERGIPE. Superintendência de Programação Econômica e orçamentária. Secretaria de Estado de Planejamento. Plano Plurianual 2008-2011: Desenvolvimento com inclusão pelo Direito e pela renda, Aracaju, 2007. Disponível em http://seplag.se.gov.br/wpcontent/uploads/2016/06/1.PPA-2008-2011-Mensagem-1.pdf. Acesso em 10 de Abril de 2014.

SERGIPE. Superintendência de Programação Econômica e orçamentária. Secretaria de Estado de Planejamento. Plano Plurianual 2012 a 2015: Sergipe, incluir para desenvolver, Aracaju, 2011. Disponível em http://seplag.se.gov.br/wp-content/uploads/2016/06/PPA-2012-2015Mensagem-e-Anexos.pdf. Acesso em 10 de Abril de 2014.

SILVA, G. Gestão pública por resultado: uma alternativa para o desenvolvimento de Alagoas? Economia política do desenvolvimento, Maceió, vol. 1, n. 5, p. 143-156, maio/ago. 2009

SILVA, E. O Pacto pela Vida no Estado de Pernambuco: Informação, política e poder. Tese (Programa de Pós-Graduação em Ciência da Informação), UFPB, 2016, 231 p. 
SILVA, G. ANJO, J. GUIMARÃES, R. Que Alagoas tem pressa? Perspectivas de reforma e modernização do Estado na Administração Pública estadual. Congresso Brasileiro de Estudos Organizacionais. Porto Alegre, RS, Brasil, 19 a 21 de Outubro de 2016.

SILVESTRE, H. Gestão Pública. Modelos de Prestação no Serviço Público. Escolar Editora, Lisboa, 2010.

SOUZA, E. Proposta de um modelo de implementação da gestão estratégica em organizações públicas com o uso integrado do Balanced Scorecard e do governo Matricial: Um estudo de caso no Ministério da Saúde. Dissertação (Mestrado Profissional). Universidade Federal da Bahia. Escola de Administração, 2008. 131 p.

TELES, J et al. Modernizando a administração pública do Estado de Sergipe: Gerenciamento Matricial de despesas. II Congresso Consad de Gestão Pública. Brasília, 2009.

\footnotetext{
${ }^{1}$ Esta breve análise estrutura um projeto de pesquisa mais amplo, realizada com auxílio financeiro do CNPq através do Edital Universal MCTI/CNPQ N $\mathrm{N}^{\circ}$ 14/2014, que investiga o desempenho dos indicadores sociais em Alagoas, Sergipe e Pernambuco nas recentes reestruturações da gestão pública.
} 